\title{
Estereologia do Miocárdio de Ratos Jovens e Idosos
}

\author{
Márcia Barbosa Águila, Carlos A lberto Mandarim-de-Lacerda, Mara Ibis Rodrigues A pfel \\ Rio de Janeiro, RJ
}

Objetivo - Comparar as diferenças quantitativas na composição e estrutura do miocárdio de ratos jovens e idosos utilizando a estereologia.

Métodos - Foram estudados 30 ratos machos da raça Wistar 15 animais jovens de 3 meses de idade e 15 animais idosos de 15 meses). Os corações foram retirados, pesados, perfundidos com solução de Bouin e posteriormente fixados em formol tamponado a $10 \%$ por $24 \mathrm{~h}$, processados por técnica histológica, incluídos em parafina, seccionados e corados pelo HE e picro-sirius. Foram analisados 15 campos aleatórios por grupo e foram determinados os seguintes parâmetros estereológicos: densidade de volume do miócito (Vv[miócito]) e densidade de volume do interstício cardíaco (Vv[interstício]) e densidade numérica dos miócitos ( $\mathrm{Nv}$ [miócito]) $\left(1 / \mathrm{mm}^{3}\right)$, estimados pelo método disector. O número total de miócitos (N[miócitos]) e a média do volume do miócito (Vol[miócito]) dos corações dos dois grupos também foram determinados. As diferenças estatísticas entre os animais jovens e idosos foram testadas pelo teste não paramétrico de Mann-Whitney.

Resultados - Comparando os animais dos grupos jovem e idoso temos, respectivamente, os seguintes dados: o peso cardíaco aumentou de 1,1 para 1,7g, o Vv(miócito) diminuiu de 76,7 para 72,2\%, Vv(interstício) aumentou de 23,3 para 27,8\%, enquanto o $\mathrm{Nv}$ (miócito) diminuiu de $14,76 \times 10^{4}$ para $6,19 \times 10^{4} / \mathrm{mm}^{3}$. O Vol(miócito) aumentou

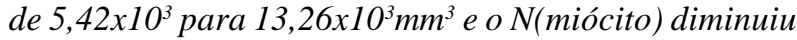

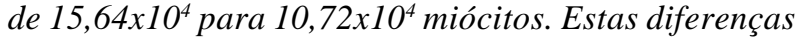
foram estatisticamente significativas $(p<0,05)$.

Conclusão - Os resultados obtidos mostram que no envelhecimento ocorre perda de miócitos cardíacos e hipertrofia das células remanescentes.

Palavras-chave: miócito, envelhecimento, estereologia

\section{Stereology of the Myocytes in Young and Aged Rats}

Purpose - To determine the myocardial quantitative changes comparing young and aged animals by using the stereology.

Methods - Thirty rat hearts were studied (15 rats aged 3 months and 15 other rats aging 15 months). The hearts were removed, weighed, fixed in $10 \%$ buffered formaldehyde solution, embedded in paraffin, cut in $7 \mu$ m thick slices and stained with HE and picro-sirius stains. In each group we counted 15 random microscopic fields. The following parameters were studied: Vv(myocyte) and $V v$ (interstitium)(\%) (the volume densities of the cardiac myocyte and interstitium, determined by the point-counting method), and $N v$ (myocyte) $\left(1 / \mathrm{mm}^{3}\right)$ (the numerical density of the cardiac myocytes, determined with the disector method). The total number of myocytes (N[myocyte]) and the mean volume of the myocytes (V[myocytes]) were also determined. The differences were tested by the Mann-Whitney test.

Results - Cardiac weight increased from 1.1 to $1.7 \mathrm{~g}$, the Vv(myocyte) decreased from 76.7 to $72.2 \%$, the $V v$ (interstitium) increased from 23.3 to $27.8 \%$. The $N v$ (myocyte) and the $N$ (myocyte) decreased from $14.76 \times 10^{4}$ to $6.19 \times 10^{4} / \mathrm{mm}^{3}$ and $15.64 \times 10^{4}$ to $10.72 \times 10^{4}$ myocytes, respectively. Simultaneously, the V(myocyte) increased from $5.42 \times 10^{3}$ to $13.26 \times 10^{3} \mathrm{~mm}^{3}$. These differences were statistically significant $(p<0.05)$.

Conclusion - Myocardial changes, comparing young rats with aged ones suggest loss of myocytes (increased apoptosis?) with simultaneous myocyte hypertrophy.

Key-words: myocyte, aging, stereology

Arq Bras Cardiol, volume 70 (nº 2), 105-109, 1998

Instituto de Biologia Roberto Alcântara Gomes da Universidade do Estado do Rio de Janeiro-UERJ e Escola de Nutrição da Universidade do Rio de Janeiro, Unidade de Nutrição Clínica, UNI-RIO.

Correspondência: Márcia Barbosa Águila - Lab. de Morfometria e Morfologia Cardiovascular - Av. 28 de Setembro, 87 (fundos) - 20551-030 Rio de Janeiro, RJ. Recebido para publicação em 25/8/97

Aceito em 25/11/97
As mudanças estruturais do miocárdio decorrente do envelhecimento ainda não estão totalmente esclarecidas na literatura médica. Sabe-se que, com o avançar da idade, há diminuição do número e hipertrofia dos miócitos cardíacos. A estereologia é um método de morfologia quantitativa que permite determinar com precisão estas alterações do miocárdio na idade avançada ${ }^{1}$. 
O miocárdio do homem adulto normal consiste de cerca de $80 \%$ de miócitos e $20 \%$, de matriz extracelular, tecido conjuntivo e vasos sangüíneos. Esta proporção é diferente em fases diferentes do desenvolvimento. Há aumento do volume relativo do miócito nas idades mais precoces da vida. Em outros casos, tais como durante a hipertrofia patológica, a proporção de colágeno e células que não são miócitos também aumentam no interstício cardíaco ${ }^{2}$.

Nos indivíduos idosos, com a perda de miócitos ocorre a simultânea queda da reserva funcional do coração, o que favorece a disfunção ventricular e a falência cardíaca nesta fase da vida. A perda crônica de miócitos reduz a capacidade do coração idoso suportar variações de pressão arterial e a sobrecarga de volume ventricular ${ }^{3}$.

A razão da perda de miócito devida à idade ainda não é conhecida, mas alguns estudos apontam que, no miocárdio, a morte celular pode ocorrer por dois mecanismos: necrose (processo acidental e passivo) e apoptose (processo programado e ativo) ${ }^{4}$.

Os atuais métodos morfológicos quantitativos são acurados e eficientes na determinação do número total de miócitos em diferentes idades ${ }^{5}$. A tentativa para estabelecer parâmetros quantitativos no coração durante o envelhecimento é de importância médica e biológica ${ }^{1,5-12}$.

Este trabalho experimental tem o objetivo de comparar as diferenças quantitativas na composição e estrutura miocárdica em dois extremos da vida de animais de laboratório (ratos Wistar): três e 15 meses de idade. Estas idades correspondem, em humanos, ao adulto jovem e ao idoso ${ }^{13}$.

\section{Métodos}

Estudou-se 30 corações de ratos Wistar. Quinze animais tinham idade de três meses (considerados animais jovens), os outros 15 animais tinham idade de 15 meses (considerados animais idosos). Os animais foram mantidos em biotério, cinco animais por caixa, com e ciclo de luz controlados. Receberam ração (purina ${ }^{\mathrm{R}}$ ) e água ad libitum.

Nas idades determinadas, os animais foram anestesiados (inalação de éter) e perfundidos, através de punção no ventrículo esquerdo (VE), com grande volume de $\mathrm{KCl}$ a $10 \%$ até a parada cardíaca em diástole.

Os corações foram retirados, seccionando-se os vasos da base próximo ao órgão, e pesados em balança analítica digital com acurácia de $0,001 \mathrm{~g}$, utilizando o método de Scherle ${ }^{14}$ (imersos em solução salina fisiológica dentro de um Becher, suspensos por um fio sem tocar nas paredes do recipiente).

Em seguida, os corações foram seccionados transversalmente ao nível do sulco coronário. Amostras do miocárdio foram retiradas da camada compacta da parede livre do VE e do septo interventricular, para tal usou-se a técnica do ortotrip ${ }^{15}$. Assim, foram obtidos cortes aleatórios e uniformemente isotrópicos.

Os fragmentos de miocárdio foram fixados em formol tamponado a $10 \%$ e, depois, desidratados em séries crescentes de álcoois, diafanizados em xilol, incluídos em parafina, seccionados em cortes de $7 \mu \mathrm{m}$ de espessura e corados pelo HE e picro-sirius.
O processamento histológico foi semelhante nos dois grupos, provocando a mesma retração tecidual. Nas diferentes etapas de preparo técnico, inclusive na clivagem do material, não observou-se diferença na rigidez do miocárdio comparando os dois grupos de estudo.

Estudou-se a densidade de volume (Vv) e a densidade numérica (Nv) dos componentes do miocárdio. Com o Vv analisou-se a ocupação relativa de estruturas miocárdicas na área-teste $\left(\mathrm{A}_{\mathrm{T}}\right)$.

O Vv do componente contráctil do miocárdio (o volume relativo do miócito no miocárdio, $\mathrm{Vv}$ [miócito]), foi considerado a célula cardíaca incluindo o núcleo. O Vv do componente não contráctil (o volume relativo do interstício cardíaco, Vv[interstício]) foi considerado como conjuntivo incluindo vasos e nervos.

Estudou-se 15 campos microscópicos aleatórios do miocárdio em cada grupo. O Vv foi determinado por contagem de pontos, considerando-se os pontos que tocavam os miócitos e interstício cardíaco de acordo com a fórmula ${ }^{6,16,17}$ :

$$
\mathrm{Vv}_{\text {(estrutura) }}=\frac{\mathrm{P}_{\mathrm{p} \text { (estrutura) }}}{\mathrm{P}_{\mathrm{T}}}
$$

sendo $\mathrm{Pp}$ [estrutura]= pontos sobre a estrutura em estudo (miócito ou interstício) e $\mathrm{P}_{\text {totais }}=42$.

O número de miócitos por volume de miocárdio (Nv[miócito]), foi determinado pelo método do disector ${ }^{18,19}$. Este método tem sido utilizado recentemente em quantificações estereológicas do miocárdio ${ }^{20-23}$. Utilizou-se um sistema de análise de imagens composto de monitor Sony Triniton $^{\mathrm{R}}$ e vídeo-microscopia com auxílio de microscópio Leica DMRBE ${ }^{\mathrm{R}}$, com objetiva 40x e câmara Kappa ${ }^{\mathrm{R}} \mathrm{CF}$ 15/5. $\mathrm{O} \mathrm{Nv}$ [miócito] foi calculado segundo a fórmula: $\mathrm{Nv}=\mathrm{Q}_{\mathrm{A}}^{-} /$ disector, sendo $\mathrm{Q}_{\mathrm{A}}$ o número de núcleos de miócitos na área-teste vistos no plano superior de corte (look-up), disector é o volume-teste, determinado multiplicando-se a espessura de microtomia pela área-teste.

O volume médio dos miócitos (V[miócitos]) foi determinado pela relação seguinte: $\mathrm{V}$ (miócito) $=\mathrm{Vv}$ (miócito $] /$ Nv(miócito).

O número total de miócitos cardíacos ( $\mathrm{N}$ [miócito]) foi calculado pelo produto do Nv(miócito) e o volume do coração (V[cor]). O V[cor] foi considerado como o peso cardíaco (P[cor]), uma vez que a gravidade específica (g) da solução salina é aproximadamente 1,0048 e o P(cor) foi aferido usando-se o método de Scherle ${ }^{14,15,19}$, isto é: $\mathrm{V}($ cor $)=\mathrm{P}($ cor $) /$ $\mathrm{g} ; \mathrm{N}$ (miócito) $=\mathrm{Nv}$ (miócito $\mathrm{x} \mathrm{V}$ (cor).

Resultados estereológicos são variáveis discretas (descontínuas), por isso testou-se as diferenças entre ratos jovens com ratos idosos, com teste não-paramétrico para amostras independentes (teste de Mann-Whitney), com nível de significância alfa de $0,05^{24}$.

\section{Resultados}

Analisando os resultados dos animais jovens e idosos, encontramos algumas diferenças que foram estatistica- 


\begin{tabular}{|c|c|c|c|c|c|c|}
\hline Grupos & Peso (g) & $\mathrm{Vv}$ (miócito)\% & Vv(interstício)\% & $\mathrm{Nv}$ (miócito) $1 / \mathrm{mm}^{3}$ & Vol(miócito)mm $\mathrm{mm}^{3}$ & $\mathrm{~N}$ (miócito) \\
\hline \multicolumn{7}{|l|}{ Jovem } \\
\hline Média & 1,1 & 76,7 & 23,2 & 147619,0 & 5418,5 & 156377,8 \\
\hline IC 95\% & 1,0 a 1,1 & 72,0 a 81,0 & 19,0 a 28,0 & 130940,8 a 164297,2 & 4644,2 a 6192,8 & 138880,9 a 173874,6 \\
\hline DP & 0,14 & 8,15 & 8,15 & 30116,94 & 1398,23 & 31595,17 \\
\hline EP & 0,04 & 2,1 & 2,1 & 7776,16 & 361,02 & 8157,84 \\
\hline $\mathrm{CV} \%$ & 12,72 & 10,65 & 34,68 & 20,4 & 25,8 & 20,2 \\
\hline $\mathrm{CE} \%$ & 3,63 & 2,75 & 8,94 & 5,27 & 6,66 & 5,22 \\
\hline \multicolumn{7}{|l|}{ Idoso } \\
\hline Média & 1,7 & 72,2 & 27,8 & 61904,8 & 13255,7 & 107166,6 \\
\hline IC 95\% & 1,63 a 1,9 & 70,48 a 75,0 & 25,02 a 29,5 & 50986,23 а 72823,2 & 10068,53 a 16442,8 & 87938,57 a 126394,7 \\
\hline DP & 0,21 & 4,06 & 4,06 & 19716,18 & 5755,24 & 34721,42 \\
\hline EP & 0,05 & 1,05 & 1,05 & 5090,70 & 1486,0 & 8965,03 \\
\hline $\mathrm{CV} \%$ & 12,35 & 5,14 & 14,87 & 31,85 & 43,42 & 32,40 \\
\hline $\mathrm{CE} \%$ & 2,94 & 1,33 & 3,85 & 8,22 & 11,21 & 8,37 \\
\hline
\end{tabular}

mente significativas $(\mathrm{p}<0,05)$. A tabela I mostra também que os coeficientes de erro (CE) foram pequenos. Apenas o Vol(miócito) teve CE de $11,21 \%$, os outros parâmetros tiveram CEabaixo de $10 \%$.

A tabela II indica que todas as diferenças estereológicas do miocárdio foram significativas comparando ratos jovens com idosos. Comparando as diferenças dos parâmetros estereológicos dos animais jovens para os animais idosos, observando as tabelas I e II, vemos que vários parâmetros apresentaram diferença significativa.

Em estudo histológico do miocárdio, observamos, nos animais idosos, áreas focais sugestivas de miocardite, com presença de células inflamatórias (macrófagos, plasmócitos), miócitos destruídos e diminuição de colágeno. Em alguns animais, haviam áreas de sugestivas de lesão antiga, já apresentando aparente substituição fibrosa. Nestas áreas, após polarização pelo método de coloração de picrosirius, observou-se aumento dos colágenos I e III.

\section{Discussão}

O conhecimento do envelhecimento cardíaco é importante para compreender melhor os processos patológicos que ocorrem mais comumente nos idosos.

O disector óptico é um método acurado para determi-

\begin{tabular}{|lcr|}
\hline \multicolumn{3}{|c|}{$\begin{array}{c}\text { Tabela II - Comparação da estereologia do miocárdio em ratos } \\
\text { jovens e ratos idosos e teste de Mann-Whitney }\end{array}$} \\
\hline Parâmetros & Jovem x idoso & Mann-Whitney \\
\hline Peso (g) & $+55 \%$ & 0,000003 \\
Vv(miócito)\% & $-6 \%$ & 0,02 \\
Vv(interstício)\% & $+19 \%$ & 0,02 \\
Nv(miócito) $1 / \mathrm{mm}^{3}$ & $-58 \%$ & 0,000003 \\
Vol(miócito)mm & $+145 \%$ & 0,000006 \\
N(miócito) & $-31 \%$ & 0,0007 \\
\hline Vv-(miócito)- densidade de volume do miócito; Nv(miócito)- densidade de \\
número do miócito; Vol(miócito)- volume total do miócito; N(miócito)- nú- \\
mero total de miócitos. \\
\hline
\end{tabular}

nações de densidade numérica de células. Neste método, um volume-teste é definido entre as faces do corte histológico. O movimento do micrométrico do microscópio define todas as estruturas contidas no volume-teste evitando a superestimação de células binucleadas ${ }^{16}$. O disector é um método tridimensional simples e sem viés. A área-teste estudada é formada obedecendo critérios que asseguram que todos os objetos são contados com a mesma probabilidade. O disector é livre do efeito de sobreposição (efeito Holmes) e do viés de "perda de calotas" quando são cortadas estruturas esféricas ${ }^{25,26}$.

As modificações estruturais do miocárdio que ocorrem nos períodos mais precoces da vida tem sido estudadas por diversos autores, inclusive em nossoLaboratório na UERJ ${ }^{8,10,20,22}$. Em um estudo utilizando o disector ${ }^{23}$ em corações de fetos humanos do $2^{\circ}$ e $3^{\circ}$ trimestre, os autores observaram que o desenvolvimento miocárdico no final do período.

Em um estudo utilizando o disector ${ }^{24}$ em corações de fetos humanos do $2^{\circ}$ e $3^{\circ}$ trimestre, os autores observaram que o desenvolvimento miocárdico no final do período fetal humano é principalmente hipertrófico para o miócito e interstício, com aumento dos peso cardíaco, Vv(interstício), $\mathrm{V}$ (miócito) e $\mathrm{N}$ (miócito) e diminuição dos $\mathrm{Vv}$ (miócito) e $\mathrm{Nv}$ (miócito).

Austin e col ${ }^{5}$, estimaram o número total de miócitos ventriculares em corações fetais e pós-natais, utilizando o método estereológico e obtiveram resultados semelhantes. Mandarim-de-Lacerda e Pessanha ${ }^{10}$, estudaram o crescimento cardíaco de ratos em três idades diferentes: embriões, fetos e neonatos. Observaram que há grande proliferação celular nestes períodos.

No coração idoso, as modificações assemelham-se à sobrecarga de pressão em termos de propriedades bioquímicas, mecânicas e eletrofisiológica ${ }^{27}$. Este fato evidencia que, no envelhecimento, existem condições que favorecem a apoptose de miócitos cardíacos. Neste estudo observamos diminuição do $\mathrm{Nv}$ (miócito) e do N(miócito) nos animais idosos, o que concorda com a existência de apoptose de miócitos cardíacos no envelhecimento. A apoptose, ou 
morte celular programada, é um processo regulado de forma ativa por células próprias destinadas à destruição. Este processo ocorre normalmente durante o desenvolvimento cardíaco, na maturação pós-natal, na hipóxia, isquemia, na sobrecarga e na insuficiência cardíaca ${ }^{4}$.

Kajstura e $\mathrm{col}^{1}$, demonstraram em ratos idosos, a ocorrência de apoptose e necrose, principalmente no VE. Observaram também que, enquanto a apoptose foi restrita ao VE, a necrose foi um fenômeno que afetou todo o coração destes animais. A necrose miocárdica envolveu, aproximadamente, 1000 miócitos na parede livre do VE aos três meses de idade e, esta perda aumentou progressivamente com o envelhecimento, alcançando um valor de 13600 miócitos aos 24 meses de idade. Levando em consideração a etiologia da perda dos miócitos, tecido de cicatrização ventricular, rarefação dos ramos intramurais da circulação coronária e crescimento hipertrófico reativo dos miócitos, estas adaptações celulares e não celulares levam ao desenvolvimento da hipertrofia encontrada nos corações idosos ${ }^{28}$. Morfometricamente, as densidades de comprimento dos vasos de resistência, de diâmetros de 6 a 20 $\mu$ m, diminuem acentuadamente aos 12 meses de idade (quando comparado com ratos de quatro meses de idade). Este fenômeno atinge as camadas interna, média e externa da parede do $\mathrm{VE}^{28}$.

Os resultados histológicos do miocárdio, através da microscopia óptica, permitiu observar áreas focais de miocardite aguda e áreas de sequielas fibrosas pós-resolução do processo agudo nos animais idosos. Este processo parece ser fisiológico, próprio do envelhecimento. No trabalho de Malinow e col ${ }^{29}$ sobre aterosclerose espontânea em ratos idosos, também foram observados evidências microscópicas de inflamação em quase todos os animais, evidenci- ando infiltração linfocitária no miocárdio e diferentes graus de fibrose.

Comparando os animais jovens com os idosos, observamos o seguinte: o peso cardíaco aumentou 55\% de três para 15 meses de idade; $\mathrm{o} V \mathrm{v}$ (miócito) diminuiu 6\% enquanto o $\mathrm{Vv}$ (interstício) $19 \%$ de três para 15 meses de idade; o $\mathrm{Nv}$ (miócito) diminuiu 58\% e o N[miócito] diminuiu 31\% de três para 15 meses de idade; $\mathrm{V}$ (miócito) aumentou $145 \%$ de três para 15 meses de idade.

Em estudo prévio descrevemos que a hipertrofia dos miócitos é mais acentuada quando ratos idosos são mantidos em dieta hiperlipídica, rica em colesterol, e menos acentuada quando os animais são mantidos em dieta com óleo de canola, rica em ácido graxo ômega-3 30,31 .

Podemos resumir os achados deste estudo, no miocárdio de ratos idosos em comparação com ratos jovens, como aumento de mais de $50 \%$ do peso do coração com simultâneo aumento, no miocárdio, do volume parcial dos miócitos e do interstício cardíaco. O volume médio do miócito aumentou e, simultaneamente, reduziu-se a densidade numérica e número total dos miócitos. O estudo utilizando o disector, permite que estas alterações devidas ao envelhecimento sejam comprovadas de forma relativamente simples e isto pode ser útil para estabelecer parâmetros quantitativos no coração. Tal conhecimento é importante no estudo do envelhecimento e na correlação com as doenças inerentes ao idoso.

\section{Agradecimentos}

O presente trabalho teve apoio do CNPq (Proc. $\mathrm{n}^{\circ}$ 52.23.73/95-0) e daFaperj(Proc. ${ }^{\circ}$ E-26/170.315/95).

\section{Referências}

1. Kajstura J, Cheng W, Sarangarajan R et al - Necrotic and apoptotic myocyte cell death in the aging heart of Fisher 344 rats. Am J Physiol 1996; 271(Heart Circ Phisiol 49): H1215-28.

2. Hudlicka O, Brown MD - Postnatal growth of the heart and its blood vessels. J Vas Res 1996; 33: 266-87.

3. Wei JY, Gersh BJ - Heart disease in the elderly. Curr Prob Cardiol 1987; 12: 1-65.

4. Brömme HJ, Holtz J - Apoptosis in the heart: when and why? Mol Cell Biochem 1996; 163/164: 261-75.

5. Austin A, Fagan DG, Mayhew TM - A stereological method for estimating the total number of ventricular myocyte nuclei in fetal and postnatal hearts $1995 ; 187$ : 641-7.

6. Mandarim-de-LacerdaCA, Santos MB, Pessanha MG-Quantitative study of the myocardium in humam embryos. Ann Anat 1995; 117: 179-84.

7. Mandarim-de-Lacerda CA-Growth alometry of the myocardium in human embryos (from stages 15 to 23). Acta Anat 1991; 141: 251-6.

8. Mandarim-de-LacerdaCA, Souza RMP-The growth of the embryonic rat myocardium (Carnegie stages 13 to 23) Ital J Anat Embryol 1994; 99: 43-55.

9. Li F, Wang X, Capasso JM, Gerdes AM-Rapid transition of cardiac myocytes from hyperplasia to hypertrophy during postnatal development. J Mol Cell Cardiol 1996; 28 : 1737-46.

10. Mandarim-de-Lacerda CA, Pessanha MG - Stereological of the myocardium in embryos, fetuses and neonates of the rat. Acta Anat 1995; 154: 261-6.

11. Chida K, Ohkawa S, Watanabe C et al - A morphoogical study of the normally aging heart. Cardiovasc Pathol 1994; 3: 1-7.
12. Olivetti G, Cigola E, Maestri R et al. - Aging, cardiac hypertrophy and ischemic cardiomyopathy do not affect the proportion of mononucleated and multinucleated myocytes in the human heart. J Mol Cell Cardiol 1996; 28: 1463-77.

13. Gerrity GR, Cliff WJ - The aortic tunica intima in young and aging rats. Exp Mol Pathol 1972; 16: 382-402.

14. Scherle W - A simple method for volumetry of organs in quantitative stereology. Mikroskopie 1970; 26: 57-63.

15. Weibel ER - Stereological methods. Pratical methods for biological morphometry. Vol 1. London: Academic Press, 1979: 415.

16. Gundersen HJG, Bagger P, Bendtsen TFet al - The new stereoloical tools: disector, fractionator, nucleator and point sampled intercepts and their use in pathological research and diagnosis. Acta Microb Imm Scand 1988-a; 96: 857-81.

17. Gundersen $\mathrm{HJG}$ - The total number of neurons in the human neocortex unbiased estimated using optical disectors. J Microsc 1988; 157: 219-27.

18. Cruz-Orive LM, Weibel EW - Recent stereological methods for cell biology: a brief survey. Am J Physiol 1990; 258: 148-56.

19. Aherne WA, Dunnill MS - Morphometry. London: Arnold, 1982: 205.

20. Santos MB, Mandarim-de-Lacerda CA - Miocárdio fetal. Proliferação do miocárdio e desenvolvimento do interstício cardíaco nos dois últimos trimestres gestacionais. Arq Bras Cardiol 1997; 68: 99-102.

21. Burity CHF, Mandarim-de-Lacerda, Pissinatti A-Stereology of the myocardium in two species of Callithrix (Callitrichidae, Primates). Ann Anat 1996; 178: 437 41.

22. Villar VC, Mandarim-de-Lacerda CA-Myocardical microvasculature in fetuses 
and neonates of rat. Stereological study. It J Anat Embryol 1995; 100: 211-8.

23. Mandarim-de-Lacerda CA, Santos MB, Le Floch-Prigent P, Narcy F-Stereology of the myocardium in human foetuses. Early Hum Develop 1997; 48: 249-59.

24. Zar JH - Biostatistical analysis. Englewood Cliffs: Prentice-Hall 1984: 718.

25. Braendgaard H, Evans SM, Howard CV, Gundersen HJG - The total numbers of neurons in the human neocortex unbiased estimated using disectors. J Microsc 1988; 157: 285-304.

26. Mayhew TM - The new stereological methods for interpreting functional morphology from slices of the cells and organs. Exp Physiol 1991; 76: 639-65.

27. Lakatta E - Heart and circulation. In: Schneider EL, Rowe JW, eds - Biology of Aging: Heart and Circulation. New York: Academic 1990: 181-216.
28. Anversa P, Li P, Sonnenblick EH et al - Effects of aging on quantitative structural properties of coronary vasculature and microvasculature in rats. Am J Physiol 1994; 267(Heart Circ Physiol 36): H1062-73.

29. Malinow MR, Hojman D, Pellegrino AA - Spontaneous atherosclerosis in the rat. Arch Pathol 1955; 13: 11-19.

30. Águila MB, Apfel MIR, Mandarim-de-Lacerda CA-Estereologia do miocárdio em ratos envelhecidos alimentados com dieta hiperlipídica é óleo de canola (rica em ácido graxo n-3). R Metab Nutr 1996; 3: 102-8.

31. Águila MB, Apfel MIR, Mandarim-de-LacerdaCA-Comparação morfológica e bioquímica entre ratos envelhecidos alimentados com dieta hiperlipídica e com óleo de canola. Arq Bras Cardiol 1997; 68: 155-61. 